\title{
ANÁLISE GENOTÓXICA DE EFLUENTE DE LAVANDERIA HOSPITALAR: ENSAIO COMETA COM Daphnia magna STRAUS, 1820
}

\author{
Fernanda Fleig Zenkner ${ }^{1}$ \\ Camila Gonçalves Athanásio ${ }^{2}$ \\ Joel Henrique Ellwanger ${ }^{3}$ \\ Daniel Prá ${ }^{4}$ \\ Alexandre Rieger ${ }^{5}$ \\ Eduardo Alexis Lobo Alcayaga ${ }^{6}$
}

\section{RESUMO}

Considerando que os efluentes hospitalares possuem carga poluidora potencialmente tóxica e genotóxica, o objetivo do presente trabalho foi desenvolver a metodologia do Ensaio Cometa com um organismo-teste amplamente utilizados em teste de toxicidade, Daphnia magna, a fim de avaliar a genotoxicidade de efluente provindo do setor de lavanderia de um hospital do Vale do Rio Pardo, RS. Foram realizadas coletas mensais do efluente entre os meses de maio e julho de 2011. Após a padronização do Ensaio Cometa, os organismos foram expostos a concentrações subletais do efluente $(0,195 ; 0,39 ; 0,78 ; 1,56 \%)$ por um período de $48 \mathrm{~h}$. O ensaio foi realizado com modificações. Os resultados mostraram diferenças significativas $(p<0,01)$ entre o controle negativo e todas as concentrações de efluente testadas. Isso sugere que mesmo diluído a 0,195\%, o efluente de lavanderia hospitalar em questão apresenta compostos com potencial de causar lesão na molécula de DNA. Assim, D. magna mostrou-se adequada para essa avaliação, bem como o Ensaio Cometa, que é essencial para complementar outros ensaios, já que apresenta maior sensibilidade, fornecendo resultados importantes para a completa avaliação de efluentes.

Palavras-chave: Ensaio Cometa. Daphnia magna. Genotoxicidade. Efluente hospitalar.

\section{ABSTRACT}

Considering that hospital waste waters present potentially toxic and genotoxic pollutants, the aim of this study was developed and applied to Daphnia magna cells the Comet Assay, as it is an animal generally employed in toxicity tests. The experiment was designed to evaluate

1 Acadêmico do curso de Ciências Biológicas e bolsista do Laboratório de Genética e Biotecnologia da Universidade de Santa Cruz do Sul (UNISC), fzenkner@gmail.com. Bolsista (PROBIC/FAPERGS).

2 Acadêmico do curso de Ciências Biológicas e bolsista do Laboratório de Ecotoxicologia da UNISC, camilaathanasio@hotmail.com. Bolsista (PROBIC/FAPERGS).

3 Bacharel em Nutrição, acadêmico do curso de Ciências Biológicas e funcionário do Laboratório de Histologia e Patologia da UNISC, joelellwanger@unisc.br.

4 Doutor em Genética e Biologia Molecular pela Universidade Federal do Rio Grande do Sul (UFRGS) e professor da UNISC, dpra@unisc.br.

5 Doutor em Genética e Biologia Molecular pela UFRGS, coordenador do Laboratório de Genética e Biotecnologia e professor da UNISC, rieger@unisc.br.

6 Pós-Doutor pelo National Institute For Resources and Environmental, coordenador do Laboratório de Limnologia e professor da UNISC, lobo@unisc.br. 
the genotoxic potential of waste water from a hospital laundry, situated in the 'Vale do Rio Pardo' region, RS. The waste water was sampled in three different months. After the assay standardization, the organisms were exposed to sub lethal waste water concentrations $(0.195 ; 0.39 ; 0.78 ; 1.56 \%)$ during a 48 hour period. The Comet Assay was adapted to $D$. magna cells. The results showed significative differences $(p<0.01)$ between the negative control and all concentrations tested. It suggests that, even at $0.195 \%$ concentration the hospital waste water is able to cause damage to the DNA. In conclusion, this study demonstrated that Comet Assay with D. magna was very effective at detecting the genotoxicity potential of waste waters, which could be important in providing an accurate data about environmental hazards caused by hospital waste water.

Keywords: Comet Assay. Daphnia magna. Genotoxicity. Hospital wastewater.

\section{INTRODUÇÃO}

A deteç̧ão de danos no DNA tem sido amplamente estudada através de métodos laboratoriais a fim de entender os tipos de lesões geradas e suas consequências em níveis mais elevados da organização biológica. As genotoxinas podem não só diminuir a expectativa de vida dos organismos, como também afetar a biodiversidade intra e interespecífica. Assim, maior entendimento sobre o tema torna-se necessário.

Enquanto as taxas de neoplasias em espécies de invertebrados são consideradas baixas quando comparadas com a incidência de tumores em peixes, isso não significa que os agentes genotóxicos não apresentam efeitos nesses organismos. Segundo Atienzar et al. (2001), em invertebrados o dano genético é manifestado como um conjunto de mudanças patológicas, a chamada "síndrome da doença genotóxica". Nesse contexto, o efeito de genotoxinas no crescimento, fecundidade, e mortalidade dos indivíduos são particularmente relevantes.

Testes de toxicidade aguda e/ou crônica normalmente utilizam o invertebrado aquático Daphnia magna Straus, 1820 (Crustacea, Cladocera), conhecido como pulga d'água, na avaliação de amostras aquosas. Esse é um organismo sensível e de fácil cultivo laboratorial, características que o torna adequando para o uso em estudos de monitoramento de efluentes.

Efluentes, como os de origem hospitalar, podem integrar ampla gama de contaminantes que se associam no descarte, gerando um efluente final potencialmente tóxico e/ou genotóxico (FERK et al., 2009). Segundo Machado et al. (2007), os efluentes gerados na lavanderia correspondem a cerca de $40 \%$ do volume de água utilizado nos leitos de hospitais situados no Vale do Rio Pardo, RS. Assim, estudos sobre o impacto ambiental de efluentes hospitalares são comumente desenvolvidos avaliando parâmetros físico-químicos e ecotoxicológicos, porém, poucos trabalhos dão enfoque ao potencial genotóxico desses.

A relevância da detecção dos riscos genotóxicos associados com a poluição da água foi primeiramente percebida no fim da década de 70, quando novos métodos foram desenvolvidos para monitorar a presença de produtos lesivos ao DNA no ambiente aquático. Esses métodos são baseados no potencial de lesões pré-mutagênicas que são passíveis de correção e não trazem maiores consequências ao organismo se forem reparadas de forma correta (FRENZILLI, NIGRO \& LYONS, 2009). Entretanto, se isso não acontecer, as quebras 
dão chances para as aberrações cromossômicas, que podem acarretar morte celular e levar a condições fisiopatológicas severas (JHA, 2008).

As alterações no DNA dos organismos podem ocasionar sérias consequências para o ecossistema, já que em nível individual lesam células e órgãos dos seres vivos, podendo afetar inclusive sua função reprodutiva, implicando danos para a população e a comunidade (BOLOGNESI \& HAYASHI, 2011). Um dos testes mais utilizados atualmente para avaliar danos no DNA é o Ensaio Cometa, que apresenta sensibilidade na detecção de lesões mesmo em organismos expostos a baixas concentrações de toxinas, além de ser realizado em células individuais não proliferativas (PRÁ et al., 2005). Adicionalmente, apresenta bons resultados a partir de um pequeno número de células analisadas (DA SILVA, HEUSER \& ANDRADE, 2003).

Frenzilli, Nigro \& Lyons (2009) apresentaram diversos estudos demonstrando que o Ensaio Cometa pode ser aplicado à ampla variedade de organismos aquáticos, proporcionando sensibilidade, rapidez e versatilidade na avaliação da genotoxicidade ambiental. Esse teste pode complementar outros ensaios como, por exemplo, os ecotoxicológicos, nos quais organismos aquáticos como $D$. magna são geralmente utilizados na avaliação de uma determinada amostra aquosa. Assim, o objetivo deste trabalho foi desenvolver a metodologia do Ensaio Cometa com esse organismo, a fim de avaliar a genotoxicidade de efluente proveniente da unidade de lavanderia de um hospital localizado na região do Vale do Rio Pardo, RS.

\section{METODOLOGIA}

\subsection{Cultivo do organismo teste}

Os neonatos de $D$. magna necessários para o estudo foram obtidos a partir de indivíduos adultos cultivados conforme a norma técnica brasileira 12713 (ABNT, 2004) no Laboratório de Ecotoxicologia da Universidade de Santa Cruz do Sul (UNISC). D. magna foram mantidas em recipientes de vidro contendo meio de cultivo M4 com foto-período de 16 horas luz e 8 horas escuro e temperatura controlada de $20^{\circ} \mathrm{C} \pm 2{ }^{\circ} \mathrm{C}$. Foram alimentados diariamente com algas da espécie Desmodesmus subspicatus. Para realização dos ensaios foram utilizados filhotes com idade entre 2 e 26 horas.

\subsection{Viabilidade celular}

A viabilidade celular foi medida utilizando o teste de exclusão com azul de tripan. Após o preparo da suspensão celular as células foram coradas com azul de tripan $0,4 \%$. Com o auxílio de Câmara de Neubauer e microscópio óptico (aumento de 1000x) foram contadas as células coradas (não viáveis) e não coradas (viáveis). O teste foi realizado em triplicata, sendo utilizadas amostras com viabilidade superior a $90 \%$.

\subsection{Suspensão celular}

A suspensão celular foi obtida por pipetagem seriada (DAVID et al., 2011) em tampão fosfato salino (PBS; $\mathrm{pH} 7,4$ ) suplementado com $20 \mathrm{mM}$ de ácido etileno diamino tetraacético (EDTA) e $50 \mu \mathrm{L}$ de dimetilsulfóxido (DMSO). As amostras foram então centrifugadas a 
2100 RPM por 10 minutos à $4 \stackrel{\circ}{ } \mathrm{C}$ e parte do sobrenadante foi descartado, resultando em 100 $\mu \mathrm{L}$ de amostra.

\subsection{Ensaio Cometa}

A metodologia do Ensaio Cometa foi desenvolvida a partir do trabalho de Park \& Choi (2007), com modificações. Para cada lâmina foram adicionados $20 \mu \mathrm{L}$ de suspensão celular e $80 \mu \mathrm{L}$ de agarose de baixo ponto de fusão. Essas permaneceram em solução de lise $(2,5 \mathrm{M}$ $\mathrm{NaCl}, 100 \mathrm{mM}$ EDTA, $10 \mathrm{mM}$ Tris, 1\% de Triton X-100, 10\% de DMSO, pH 10,0) por $1 \mathrm{~h}$. A eletroforese foi conduzida durante 15 minutos $(0,7 \mathrm{~V} / \mathrm{cm}$ e $300 \mathrm{~mA})$ em tampão com pH \pm 12 . Após neutralização e fixação, a coloração foi realizada com solução a base de nitrato de prata. As lâminas foram analisadas em microscópio óptico convencional (aumento de 400x), sendo contadas 100 células por lâmina, em um total de 400 células por amostra. As células foram classificadas de acordo com Tice et al. (2000), sendo calculados Índice (ID) e Frequência de Dano (FD). Os dados foram avaliados pela análise de variância (ANOVA) com pós-teste de Bonferroni no programa estatístico GraphPad Prism 5.01.

\subsection{Coleta e avaliação de efluente hospitalar}

Foram realizadas coletas mensais, entre os meses de maio e julho de 2011 , de efluente proveniente do setor de lavanderia de um hospital localizado na região do Vale do Rio Pardo, RS. Alíquotas do efluente foram congeladas seguindo as normas vigentes na legislação para posterior realização dos testes de toxicidade aguda e genotoxicidade com $D$. magna.

A concentração subletal do efluente foi determinada a partir do teste de toxicidade aguda realizado com o efluente bruto diluído cerca de dez vezes. Primeiramente o efluente foi avaliado na concentração de 1,56\% (concentração subletal). Após, maiores diluições foram feitas, realizando-se os ensaios com as concentrações de 1,56;0,78;0,39 e 0,195\%. Cada concentração foi avaliada em duplicada, sendo utilizados 20 indivíduos, os quais foram expostos por 48 horas. Acompanhando cada teste utilizou-se um controle negativo e um positivo. O controle positivo consistiu em indivíduos expostos a uma solução de sulfato de cobre $\left(0,12 \mathrm{mg} . \mathrm{L}^{-1}\right)$ pelo mesmo período utilizado para o efluente.

\section{RESULTADOS E DISCUSSÃO}

O Ensaio Cometa com D. magna mostrou que o efluente proveniente do setor de lavanderia hospitalar sofre variação de genotoxicidade dependendo da demanda mensal do hospital. Os resultados podem ser visualizados na Tabela 1, onde estão organizados pelo mês de coleta. 
Tabela 1 - Resultados dos ensaios realizados com Daphnia magna expostas a diferentes diluições do efluente do setor de lavanderia de hospital do Vale do Rio Pardo, RS, coletado em três meses do ano de 2011.

\begin{tabular}{ccccccc}
\hline \multicolumn{5}{c}{ Mês } & \multicolumn{5}{c}{ TRATAMENTOS } \\
\hline Maio & & & $\mathbf{1 , 5 6 \%}$ & $\mathbf{0 , 7 8 \%}$ & $\mathbf{0 , 3 9 \%}$ & $\mathbf{0 , 1 9 5 \%}$ \\
& ID & $23 \pm 8,29$ & $177,25 \pm 25,33$ & - & - & - \\
& FD & $12,75 \pm 4,57$ & $58,25 \pm 3,5$ & - & - & - \\
Junho & & & & & & \\
& ID & $18,67 \pm 7,57$ & $177,25 \pm 17,73$ & $136,5 \pm 21,67$ & $127,25 \pm 34,09$ & $108,33 \pm 13,05$ \\
& FD & $8,67 \pm 3,51$ & $54,25 \pm 3,4$ & $47,5 \pm 4,8$ & $44 \pm 8,49$ & $38,67 \pm 3,06$ \\
Julho & & & & & & \\
& ID & $18 \pm 1,63$ & $116 \pm 4,36$ & - & - & $99,67 \pm 25,15$ \\
& FD & $11,5 \pm 1,29$ & $40 \pm 1$ & - & - & $33,67 \pm 6,35$ \\
\hline
\end{tabular}

$\mathrm{CN}=$ Controle Negativo; ID= Índice de Dano; FD= Frequência de Dano;

Em todos os meses, os resultados mostraram diferenças significativas $(p<0,05)$ entre $o$ controle negativo e todas as concentrações de efluente testadas, tanto para ID como para FD. No mês de junho, quando foram testadas quatro diluições do efluente, somente as concentrações de 1,56\% e 0,195\% apresentaram diferenças estatisticamente significativas entre si (Figura 1) devido ao efeito de diluição. Contudo, mesmo a menor concentração ainda apresenta genotoxicidade significativamente aumentada em relação ao controle negativo.

Figura 1 - Índice de Dano encontrado em Daphnia magna expostas a diferentes diluições de efluente do setor de lavanderia hospitalar coletado no mês de junho de 2011.

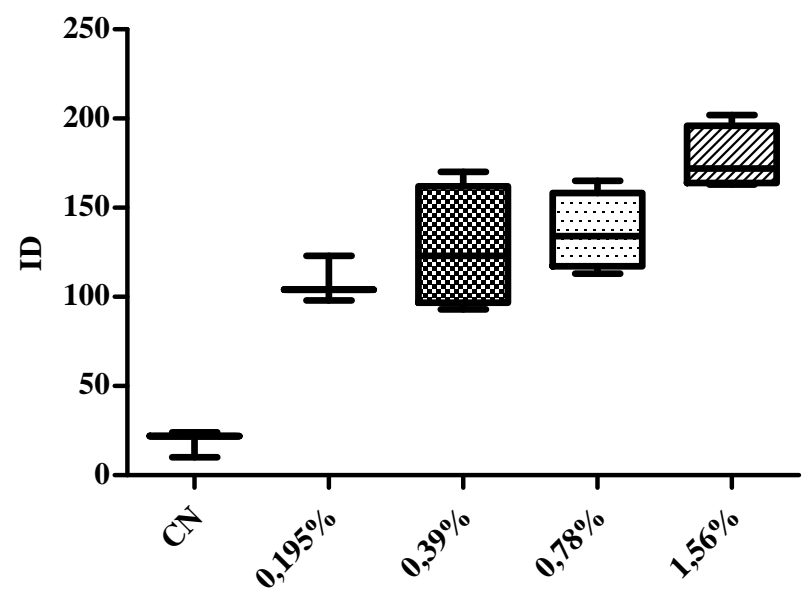

$\mathrm{CN}=$ Controle Negativo; ID= Índice de Dano.

Assim, mesmo quando diluído a $0,195 \%$, os resultados indicam que o efluente apresenta compostos com potencial de causar lesão na molécula de DNA. Pode-se observar na Figura 2 que à medida que o efluente é mais concentrado, diminuem as células sem dano (classe 0 ) e cada vez mais nucleóides com dano máximo (classe 4) são encontrados. 
Figura 2 - Distribuição dos nucleóides nas 5 classes de dano segundo os dados do Ensaio Cometa.

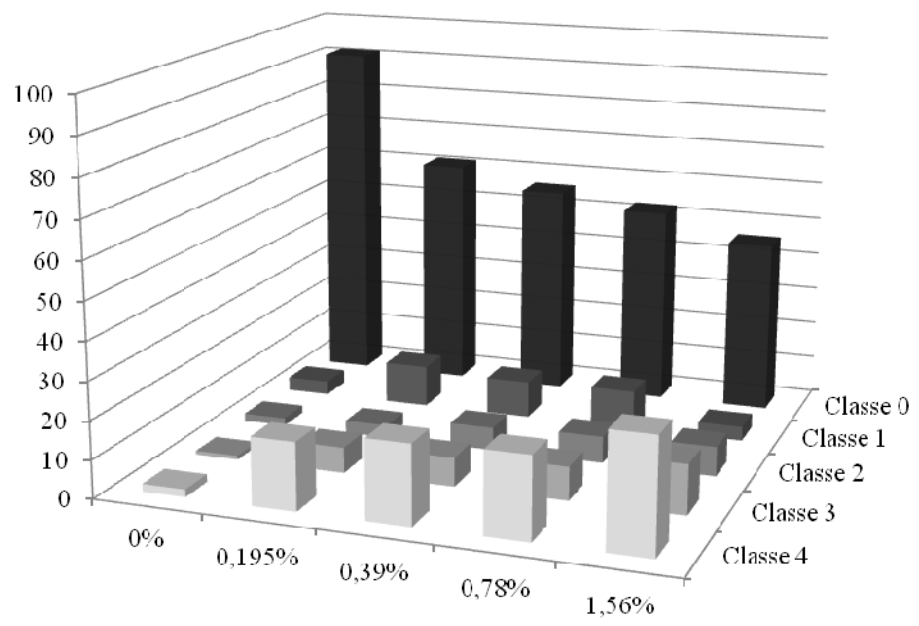

Comparando os resultados encontrados nos três meses em que o efluente foi avaliado a 1,56\%, percebe-se que no último mês esse não manteve o mesmo efeito genotóxico nas células de $D$. magna. Os Índices de Dano para essa concentração em maio e junho não diferiram estatisticamente entre si, já o encontrado no mês de julho foi significativamente menor $(p<0,05)$, mostrando variação da toxicidade neste mês (Figura 3).

Figura 3 - Comparação entre os Índices de Dano encontrados em Daphnia magna expostas ao efluente do setor de lavanderia hospitalar diluído a $1,56 \%$ coletado nos meses de maio, junho $\left({ }^{*}\right)$ e julho $\left({ }^{* *}\right)$ de 2011.

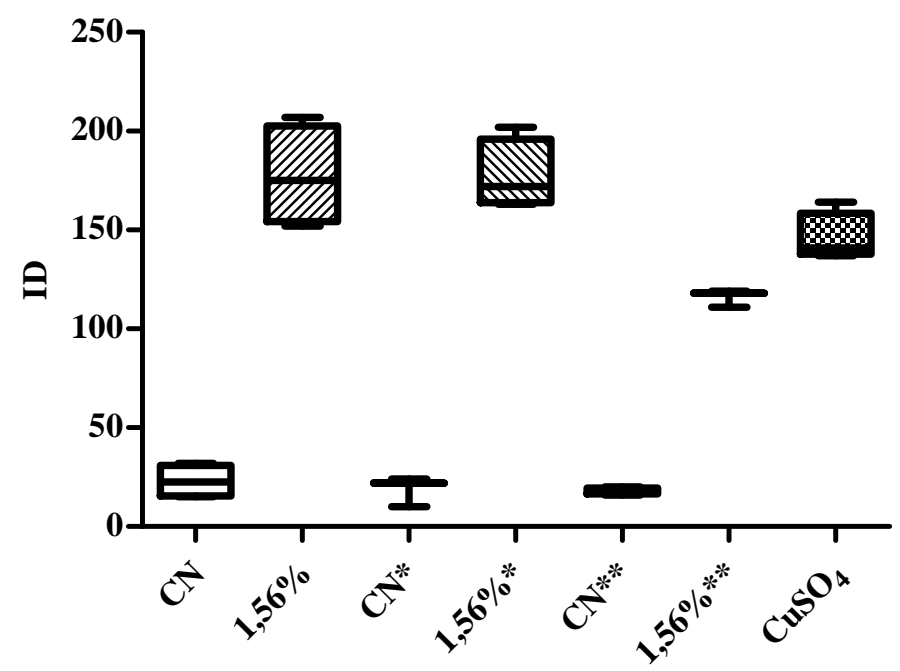

$\mathrm{CN}=$ Controle Negativo; ID= Índice de Dano; $\mathrm{CuSO}_{4}=$ sulfato de cobre a 0,12 mg. $\mathrm{L}^{-1}$.

Como controle positivo de genotoxicidade foi utilizado sulfato de cobre $\left(\mathrm{CuSO}_{4}\right)$ na concentração de $0,12 \mathrm{mg} \cdot \mathrm{L}^{-1}$. Sabe-se que o cobre se liga a proteínas e ácidos nucléicos das células causando lesões, além de aumentar a formação de radicais livres, promovendo citotoxicidade e genotoxicidade (CHAIRI et al., 2010). O $\mathrm{CuSO}_{4}$ foi capaz de induzir danos ao 
DNA de D. magna, mostrando-se um bom controle positivo. Pode-se observar que o ID da amostra exposta ao $\mathrm{CuSO}_{4}$ apresentou-se estatisticamente diferente do controle negativo em todos os momentos. Além disso, quando comparado ao efluente hospitalar não foram encontradas diferenças entre os ID das amostras, mais uma vez sugerindo a genotoxicidade do efluente testado (Figura 3).

Ferk et al. (2009) discutiram sobre a avaliação da genotoxicidade de efluentes hospitalares através da utilização de ensaios como o Teste de Ames e o Ensaio Cometa com células de mamíferos. No trabalho foi sugerido que o potencial genotóxico desses efluentes pode estar relacionado com diversas substâncias, como resíduos de drogas antineoplásicas e o glutaraldeído utilizado na desinfecção de materiais hospitalares. Porém, deve-se levar em consideração que os agentes genotóxicos variam conforme a ala da qual o efluente provém. No presente estudo essas substâncias estão em fase de investigação, o que possibilitará um melhor tratamento do efluente antes do seu descarte no meio.

\section{CONCLUSÃO}

Os aspectos modificados na etapa de preparação das suspensões celulares mostraramse essenciais na obtenção de resultados confiáveis a partir do EC, sendo que possíveis danos mecânicos ao DNA durante o preparo foram evitados. Quanto ao efluente hospitalar, mesmo que no último mês esse tenha apresentado menor genotoxicidade a 1,56\%, os organismos expostos à concentração de $0,195 \%$ continuaram com maior ID em relação ao controle negativo. Assim, seria interessante avaliar o efluente em diluições superiores às utilizadas neste trabalho para determinar a partir de qual concentração o mesmo não apresenta potencial genotóxico para D. magna. O Ensaio Cometa, em conjunto com análises físico-químicas e ecotoxicológicas, pode proporcionar a caracterização completa de efluentes antes e depois de serem tratados e descartados no ambiente.

\section{REFERÊNCIAS}

ABNT. Associação Brasileira de Normas Técnicas. NBR 12713: Ecotoxicologia Aquática Toxicidade Aguda - Método de ensaio com Daphnia spp. (Cladocera, Crustacea). Rio de Janeiro, 2004. 21p.

ATIENZAR, F. A.; CHEUNG, V. V.; JHA, A. N.; DEPLEDGE, M. H. Fitness parameters and DNA effects are sensitive indicators of copper-induced toxicity in Daphnia magna. Toxicological sciences, v. 59, p. 241-250, 2001.

BOLOGNESI, C.; HAYASHI, M. Micronucleus assay in aquatic animals. Mutagenesis, v. 26, n. 1, p. 205-213, 2011.

CHAIRI, H.; FERNÁNDEZ-DIAZ, C.; NAVAS, J. I.; MACHADO, M.; REBORDINOS, L.; BLASCO, J. In vivo genotoxicity and stress defences in three flatfish species exposed to $\mathrm{CuSO}_{4}$. Ecotoxicology and Environmental Safety, v. 73, p. 1279-1285, 2010. 
DA SILVA, J., HEUSER, V., ANDRADE, V. Biomonitoramento Ambiental. In: DA SILVA, J., ERDTMANN, B.; HENRIQUES, J. A. P. (Org.). Genética Toxicológica. Porto Alegre: Alcance, p. 167-180, 2003.

DAVID, R. M.; DAKIC, V.; WILLIAMS, T. D.; WINTER, M. J.; CHIPMAN, K. Transcriptional responses in neonate and adult Daphnia magna in relation to relative susceptibility to genotoxicants. Aquatic Toxicology, v. 104, p. 192-204, 2011.

FERK, F.; MISIK, M.; GRUMMT, T.; MAJER, B.; FUERHACKER, M.; BUCHMANN, C.; VITAL, M.; UHL, M.; LENZ, K.; GRILLITSCH, B..; PARZEFALL, W.; NERSESYAN, A.; KNASMÜLLER, S. Genotoxic effects of wastewater from an oncological ward. Genetic and Environmental Mutagenesis, v. 672, p. 69-75, 2009.

FRENZILLI, G.; NIGRO, M.; LYONS, B. P. The Comet assay for the evaluation of genotoxic impact in aquatic environments. Mutation Research, v. 681, p. 80-92, 2009.

JHA, A. N. Ecotoxicological applications and significance of the comet assay. Mutagenesis, v. 23, n. 3, p. 207-221, 2008.

MACHADO, E.L. ; KIST, L. T.; SCHMIDT, R.; HOELTZ, J. M.; DALBERTO, D.; ALCAYAGA, E. L. A. Secondary Hospital Wastewater Detoxification and Disinfection by Advanced Oxidation Processes. Environmental Technology, V. 28, p. 1135-1143, 2007.

PARK, S. Y.; CHOI, J. Cytotoxicity, genotoxicity and ecotoxicity assay using human cell and environmental species for the screening of the risk from pollutant exposure. Environmental International, v. 33, p. 817-822, 2007.

PARK, S. Y.; CHOI, J. Genotoxic Effects of Nonylphenol and Bisphenol A Exposure in Aquatic Biomonitoring Species: Freshwater Crustacean, Daphnia magna, and Aquatic Midge, Chironomus riparius. Bulletin of Environmental Contamination and Toxicology, v. 83, p. 463468, 2009.

PRA, D., LAU, A. H., KNAKIEVICZ, T., CARNEIRO, F. R., ERDTMANN, B. Environmental genotoxicity assessment of an urban stream using freshwater planarians. Mutation Research. Genetic Toxicology and Environmental Mutagenesis, 585(1-2): 79-85, 2005.

TICE, R; AGURELL, E.; ANDERSON, D.; BURLINSON, B.; HARTMANN, A.; KOBAYASHI, H.; MIYAMAE, Y.; ROJAS, E.; RYU, J. C.; SASAKI, Y. F. Single cell gel/comet assay: guidelines for in vitro and in vivo genetic toxicology testing. Environmental and Molecular Mutagenesis, v. 35, p. 206-221, 2000.

\section{Agradecimentos}

Os autores agradecem a Fundação de Apoio a Pesquisa do Rio Grande do Sul (FAPERGS) pela bolsa concedida à primeira autora, e à Universidade de Santa Cruz do Sul (UNISC) pela infraestrutura fornecida. 